\title{
Spectral induced polarization and electrodic potential monitoring of microbially mediated iron sulfide transformations
}

\author{
Yves Robert Personna, ${ }^{1}$ Dimitrios Ntarlagiannis, ${ }^{1,2}$ Lee Slater, ${ }^{1}$ Nathan Yee, ${ }^{3}$ Michael O’Brien, ${ }^{1}$ and \\ Susan Hubbard ${ }^{4}$ \\ ${ }^{1}$ Department of Earth and Environmental Sciences, Rutgers University, Newark, New Jersey, USA \\ ${ }^{2}$ Nowat School of Planning, Architecture, and Civil Engineering, Queen's University Belfast, Belfast, UK \\ ${ }^{3}$ Department of Environmental Sciences, Rutgers University, New Brunswick, New Jersey, USA. \\ ${ }^{4}$ Lawrence Berkeley National Laboratory, Earth Sciences Division, Berkeley, California, USA.
}

[1] Stimulated sulfate-reduction is a bioremediation technique utilized for the sequestration of heavy metals in the subsurface.We performed laboratory column experiments to investigate the geoelectrical response of iron sulfide transformations by Desulfo vibriovulgaris. Two geoelectrical methods,(1)spectral induced polarization (SIP), and (2) electrodic potential measurements, were investigated. Aqueous geochemistry (sulfate, lactate, sulfide, and acetate), observations of precipitates (identified from electron microscopy as iron sulfide), and electrodic potentials on bisulfideion (HS) sensitive silver-silver chloride (Ag-AgCl) electrodes $(630 \mathrm{mV}$ ) were diagnostic of induced transitions between an aerobic iron sulfide forming conditions and aerobic conditions promoting iron sulfide dissolution. The SIP data showed 10m rad anomalies during iron sulfide mineralization accompanying microbial activity under an anaerobic transition. These anomalies disappeared during iron sulfide dissolution under the subsequent aerobic transition. SIP model parameters based on a Cole-Cole relaxation model of the polarization at the mineralfluid interface were converted to (1) estimated biomineral surface area to pore volume (Sp), and (2) an equivalent polarizable sphere diameter (d) controlling the relaxation time. The temporal variation in these model parameters is consistent with filling and emptying of pores by iron sulfide biofilms, as the system transitions between anaerobic (pore filling) and aerobic (pore emptying) conditions. The results suggest that combined SIP and electrodic potential measurements might be used to monitor spatiotemporal variability in microbial iron sulfide transformations in the field.

\section{Introduction}

[2] Soil and groundwater contamination by acid-mine drainage, industrial sources, and government nuclear weapon programs pose threats to human health and the environ-ment. Such anthropogenic activities may deliver into the environment a variety of substances of significant toxicity, carcinogenicity and potential for bioaccumulation in living systems. Microbial driven remediation (bio-remediation) has attracted interest in recent years as an effective cleanup technology [Rittle et al., 1995; Schultze-Lametal., 1996; Drury, 1999; Ehrlich, 1999; Drzyzga et al., 2002]. Biore-mediation techniques can offer an efficient, safe and cost effective option for the removal of hazardous pollutants without production of hazardous byproducts [Providentietal., 1993; Ward et al., 2003]. However, observational methods that enable realtime,spatially accurate monitoring and assessment of biological processes at the field scale are lacking.

[3] One successful remediation strategy involves common soilborne microorganisms, such as Desulfo vibriovulgaris (D.vulgaris) studied here, to mineralize toxic metals in solution [Lovley et al., 1993; Anderson et al., 2003]. Williams et al. [2005] and Ntarlagiannis et al. [2005] showed that electrical and acoustic geophysical methods are sensitive to the formation of insoluble precipitates, or biominerals often associated with such remediation strategies. They suggested that geophysical techniques could be employed to monitor such bioremediation strategies in situ. Others have demonstrated the potential of geophysics to elucidate system transformations occurring during bioremediation of hydrocarbon contaminants [Atekwana et al., 2000, 2004]. Werkema et al. [2003] showed that zones of microbial degradation coincided with elevated soil electrical conductivity whereas Abdel Aal et al. [2004] showed that microbial activity enhances 
the low-frequency polarizability of soils. Others have shown how natural electrical signals are diagnostic of microbialgenerated redox fronts in landfills [Naudet et al., 2003, 2004] and hydrocarbon contaminated sites [Minsley et al., 2007].

[4] Here we report on the biogeophysical signatures associated with microbial-driven iron sulfide transformations. The experiment extends the work of Ntarlagiannis et al. [2005] and Williams et al. [2005] by (1) inducing iron sulfide biomineral transformations across both anaerobic and aerobic transitions; (2) examining spatial variability in the biogeophysical response in relation to variable rates of biomineralization within a column; and (3) modeling the geoelectrical signals resulting from biomineral-induced changes in terms of geometrical properties of the pore space. We employ both the spectral induced polarization (SIP) method, which is sensitive to biomineral formation [Ntarlagiannis et al., 2005; Williams et al., 2005] and a variant of an electrodic potential measurement that uses a pair of $\mathrm{Ag}-\mathrm{AgCl}$ electrodes whereby both electrodes are in direct contact with the column fluid [Williams et al., 2007]. These electrodic measurements are sensitive to the concentration of dissolved sulfide [Berner, 1963]. We discuss the relative sensitivity of electrodic potential and SIP measurements to microbial-induced iron sulfide mineralization, the stability of iron sulfide biominerals to aerated conditions, differences in the geophysical signatures between anaerobic and aerobic transitions, and the significance of modeled SIP parameters in terms of biomineral-induced changes in porescale geometric parameters.

\section{Spectral Induced Polarization}

[5] The SIP method measures the frequency-dependent electrical response of soils at frequencies $<1 \mathrm{KHz}$. The method was developed primarily for locating disseminated metallic ores [Marshall and Madden, 1959; Sumner, 1976], but has more recently been used for environmental applications [Ward et al., 1995; Slater and Lesmes, 2002], such as the characterization of metal containing soils [Williams et al., 2005; Slater et al., 2005; Wu et al., 2005; Slater and Binley, 2006; Wu et al., 2006; Mansoor and Slater, 2007]. In the SIP method the impedance magnitude and phase shift $\phi$ of the sample are recorded relative to a reference resistor following current injection (typically a swept sine wave) [e.g., Slater and Lesmes, 2002]. The measured magnitude and phase can be converted into a measured complex conductivity $\left(\sigma^{*}\right)$, complex resistivity $\left(\rho^{*}\right)$ or complex dielectric permittivity $\left(\varepsilon^{*}\right)$ if the geometric factor defining the measurement geometry and the resulting current flow path are considered known. Here we represent the measured data in terms of measured resistivity $(|\rho|)$ and $\phi$,

$$
\begin{gathered}
|\rho|=\sqrt{\left(\rho^{\prime 2}+\rho^{\prime \prime 2}\right),} \\
\phi=-\tan ^{-1}\left[\frac{\rho^{\prime \prime}}{\rho^{\prime}}\right],
\end{gathered}
$$

where single superscript represents the real part (an energy loss term), and double superscript represents the imaginary part (polarization or energy storage term) of $\rho^{*}$.
[6] At the low frequencies measured with SIP $(<1 \mathrm{kHz})$, energy loss via ionic and electronic conduction dominates. Ionic conduction results from electrolytic conduction in the fluid-filled interconnected pore space [Archie, 1942] as well from surface conduction via the formation of an electrical double layer (EDL) at the grain-fluid interface [e.g., Revil and Glover, 1997, 1998]. Electronic conduction results when metallic minerals form continuous conductive pathways. In the SIP frequency range the energy storage results primarily from the polarization of the ions in the EDL at the mineral-fluid interface. The magnitude of this polarization scales with the surface area to pore volume $\left(S_{p}\right)$ [Slater et al., 2006] whereas the time constant $(\tau)$ describing the length-scale of the relaxation is recognized as a function of the pore or grain size characteristics of soils [e.g., Olhoeft, 1985; Chelidze and Gueguen, 1999], which is consistent with electrochemical theory for colloidal suspensions [Schwarz, 1962]. Wong [1979], in constructing a theoretical model, attributed the polarization in metallic soils when the metal is less than $10 \%$ of the soil volume to 1) diffusion of redox active and inactive ions predominantly perpendicular to the metal surface under an applied electric field, and 2) an electrochemical mechanism associated with redox active ions facilitating transport of charge between ionic and electronic conduction. However, this eight-parameter theoretical model requires the definition of electrochemical parameters that are typically poorly determined.

[7] Given the lack of easily applied theoretical models to adequately describe the SIP response of natural soils, phenomenological formulations, such as the Cole-Cole relaxation model, are often applied [Pelton et al., 1978, 1983; Binley et al., 2005; Slater et al., 2006]. One form of the Cole-Cole model commonly used in geophysical exploration is,

$$
\rho^{*}=\rho_{0}\left[1-m\left(1-\frac{1}{1+(i \omega \tau)^{c}}\right)\right],
$$

where $\rho_{0}$ is the dc resistivity (inverse of dc ohmic conductivity), $m$ is the chargeability, $\tau$ is the characteristic time constant, $c$ is a shape parameter (typically between 0.2 and 0.7 in unconsolidated soils) and $i=\sqrt{-1}$ [Pelton et al., 1978].

\section{Electrodic Potential Measurements}

[8] Metallic electrodes are routinely used to measure redox potential $(\mathrm{eH})$ and $\mathrm{pH}$, whereby the potential difference between the electrode in contact with the solution and a reference electrode connected to the solution by a salt bridge is recorded. Such electrodic measurements have been performed to track microbial mediated chemical changes in marine sediments [Zobell, 1946; Emery and Rittenberg, 1952; Baas-Becking et al., 1960] and have increasingly been applied in the analysis of sulfide compounds [Berner, 1963; Whitfield, 1971; Luther et al., 2001].

[9] In this paper, we apply the electrodic potential approach as a simple, direct contact method to capture spatiotemporal variations in aqueous sulfide concentrations resulting from sulfate reduction by $D$. vulgaris within an experimental column. The method is based on the well- 

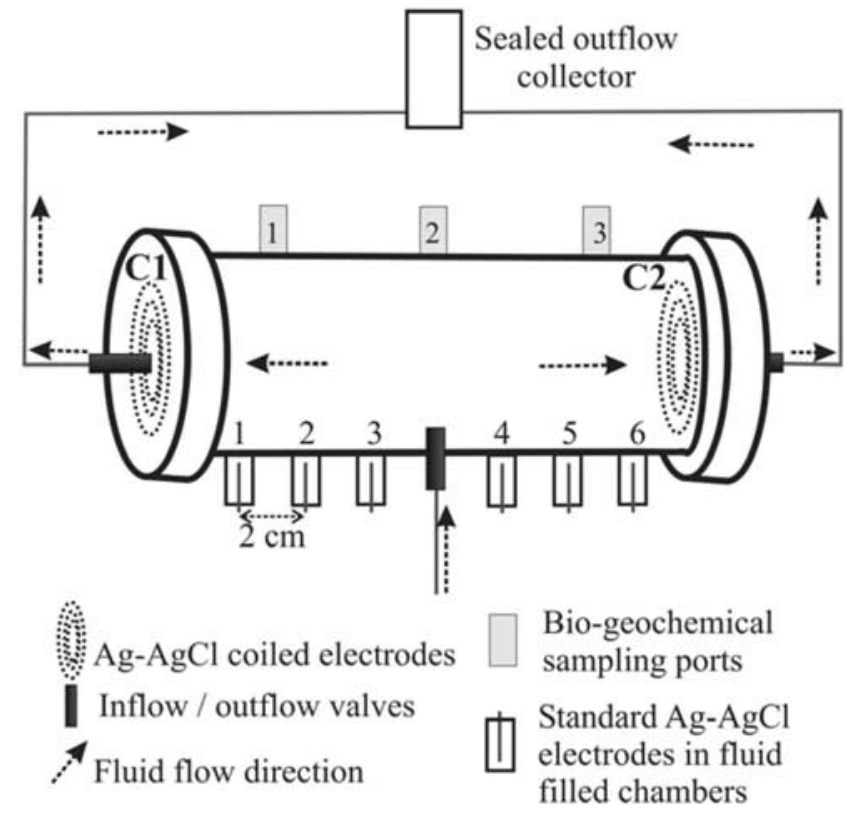

Figure 1. Schematic of column setup showing flow through configuration, location of $\mathrm{Ag}-\mathrm{AgCl}$ electrodes (SIP and electrodic potential), SIP current injection and electrodic potential reference coiled electrodes, and biogeochemical sampling ports.

known reactivity of $\mathrm{Ag}-\mathrm{AgCl}$ electrodes and $\mathrm{HS}^{-}$ions in anaerobic environments [Berner, 1963]. Williams et al. [2007] used a pair of $\mathrm{Ag}-\mathrm{AgCl}$ electrodes to record a galvanic cell (GC) potential that exists when the electrodes straddle a gradient in bisulfide ion $\left(\mathrm{HS}^{-}\right)$concentration. Oxidation of the $\mathrm{Ag}-\mathrm{AgCl}$ anode results from a half-cell reaction in the presence of elevated $\mathrm{HS}^{-}$concentrations (relative to cathode), while reduction of the $\mathrm{AgCl}$ electrode coating occurs at the cathode. The anode effectively becomes an $\mathrm{Ag}-\mathrm{Ag}_{2} \mathrm{~S}$ electrode (equation (4) below). When connected between these electrodes a voltmeter records an open circuit potential caused by the difference in $\mathrm{HS}^{-}$ concentration at the local fluid-electrode interface between the two electrode locations. This open circuit potential is a measure of the tendency of a spontaneous reaction between these electrodes to proceed (significant current flow does not occur due to the high input impedance of the voltmeter). The open circuit potential between the $\mathrm{Ag}-\mathrm{AgCl}$ electrode pair increases with an increase in the $\mathrm{HS}^{-}$concentration difference between the two electrodes [Williams et al., 2007]. The equations describing the two reactions are,

$$
\begin{gathered}
2 \mathrm{Ag}^{0}+\mathrm{HS}^{-} \longrightarrow \mathrm{Ag}_{2} \mathrm{~S}+\mathrm{H}^{+}+2 \mathrm{e}^{-} \text {(Anode) } \\
2 \mathrm{AgCl}+2 \mathrm{e}^{-} \longrightarrow 2 \mathrm{Ag}^{0}+2 \mathrm{Cl}^{-}(\text {Cathode })
\end{gathered}
$$

\section{Materials and Methods}

[10] We performed a two phase column experiment under (1) anaerobic conditions (an atmosphere of $95 \% \mathrm{~N}_{2}$ and $5 \% \mathrm{H}_{2}$ ) to investigate the geoelectrical responses associated with iron sulfide mineralization during stimulated sulfate- reduction by a pure culture of $D$. vulgaris, followed by (2) aerobic conditions to investigate the subsequent response associated with iron sulfide dissolution. The experiment design is schematically illustrated in Figure 1. The anaerobic transition and anaerobic phase of the experiment were conducted in an anaerobic chamber whereas the subsequent aerobic transition was initiated by opening the anaerobic chamber to the atmosphere, thereby promoting possible oxidation of both sulfide and $\mathrm{Fe}^{2+}$ by oxygen. We define three primary system states to aid interpretation of the data: (1) the anaerobic transition $(t=1-24 \mathrm{~d})$, (2) the anaerobic phase ( $t=25-36 \mathrm{~d})$, and (3) the aerobic transition $(t=37-55 \mathrm{~d})$ primarily based on the mineralization efficiency of $D$. vulgaris.

[11] Prior to the experiment, the ability of $D$. vulgaris to reduce sulfate and induce iron sulfide precipitation was tested by injecting 1 to $2 \mathrm{~mL}$ of a microbial solution in several tubes containing different dilutions $(10 \%-100 \%)$ of an enriched version of a growth medium. This growth medium was known to support the growth of $D$. vulgaris and resembled metal and sulfate contaminated groundwater amended with a source of organic carbon [Williams et al., 2005]. The primary constituents of the medium were: lactate $4 \mathrm{mM}$, sulfate $4 \mathrm{mM}\left(80 \% \mathrm{Na}_{2} \mathrm{SO}_{4}\right.$ and $\left.20 \% \mathrm{MgSO}_{4}\right)$, and $\mathrm{FeSO}_{4} 125 \mu \mathrm{M}$ as $\mathrm{Fe}(\mathrm{II})$ source. For the anaerobic phase of the experiment, this solution was made anoxic and sterile by boiling and then cooling under $\mathrm{N}_{2}$ gas before being autoclaved. It was kept open to ambient air (through a $0.45 \mu \mathrm{m}$ filter) during the later aerobic phase, allowing $\mathrm{O}_{2}$ to diffuse into the column to facilitate the development of aerated conditions. Sulfate reduction was observed at all dilutions tested. The microbially induced iron sulfide precipitation can be described as a two-step chemical reaction process initiated by the activity of $D$. vulgaris, utilizing lactate as an electron donor and sulfate as an electron acceptor under anaerobic conditions:

$$
\begin{aligned}
2 \mathrm{CH}_{3} \mathrm{CHOHCOO}^{-} & +\mathrm{SO}_{4}^{2-} \stackrel{\mathrm{D.vul} \lg \text { aris }}{\longrightarrow} 2 \mathrm{CH}_{3} \mathrm{COO}^{-} \\
& +2 \mathrm{HCO}_{3}^{-}+\mathrm{H}_{2} \mathrm{~S} \\
\mathrm{Fe}^{2+} & +\mathrm{H}_{2} \mathrm{~S}_{(\text {(qqueous })} \longrightarrow \mathrm{FeS}_{(\text {solid })}+2 \mathrm{H}^{+}
\end{aligned}
$$

[12] All inoculated tubes showed visible black precipitates in $\sim 5 \mathrm{~d}$, whereas no changes were observed for control tubes in which no cells were injected.

[13] Two experimental columns (EC1 and EC2) were constructed with an inner diameter of $3.17 \mathrm{~cm}$ and a length of $20.3 \mathrm{~cm}$, each accommodating six $\mathrm{Ag}-\mathrm{AgCl}$ electrodes housed in electrolyte-filled ports attached along one column side (Figure 1). As is also shown in the figure, three fluid sampling ports were emplaced on opposite sides of the columns. Two $\mathrm{Ag}-\mathrm{AgCl}$ coiled electrodes $(\mathrm{C} 1$ and $\mathrm{C} 2)$ were attached at the ends of the columns to enable injection of a one-dimensional current through the column (note that these also served as electrodic potential electrodes) (Figure 1). Columns were dry-packed with silica sand $\left(99.8 \% \mathrm{SiO}_{2}\right.$; $d_{50}=0.3 \mathrm{~mm}$; average porosity $=37.2 \pm 1 \%$ ) and gentle tapping was performed to minimize grain sorting. This sand was previously chemically treated to remove organic traces [Bartlett et al., 1937], and iron oxide impurities by using a mixture of sodium citrate (44 g), sodium bicarbonate (42 g), 
sodium dithionite $(20 \mathrm{~g}), 500 \mathrm{~mL}$ of deionized water (DIW), and sodium chloride (added until saturation) [Mehra and Jackson, 1960]. The treated sand was rinsed several times with DIW, dried at $90^{\circ} \mathrm{C}$, and autoclaved. Saturated, sandpacked columns were flushed with sterile $\mathrm{N}_{2}$ gas to remove entrapped air bubbles. To minimize contamination all materials used during the experiment were sterilized following common sterilization protocols. Experiment materials (fluids, sand matrix, tubing) were autoclaved, with PVC column parts that were not autoclavable sterilized in ethanol $(>95 \%)$.

[14] The columns were then placed in a horizontal position. The growth medium entered the column through a dedicated port at the column center and exited it through ports on both column ends (Figure 1). This configuration was preferred over vertical column configuration having an inflow at one end because such a setup previously resulted in biomineralization occurring primarily at the column end containing the inflow, which complicated SIP interpretation [Williams et al., 2005]. In contrast, the configuration employed here ensured that the biomineralization occurred within the support volume of the SIP measurement (defined by the distance between $\mathrm{Ag}-\mathrm{AgCl}$ Electrodes 1-6). We assume complete pore cycling during early experiment time but recognize the possibility of flow-bypassing of dead end zones as a result of heterogeneous biomineral formation.

[15] To provide a geochemical/geophysical baseline, we first flushed columns with the anaerobic growth medium over a period of $5 \mathrm{~d}$, with samples collected daily at the inflow and the middle ports and geophysical measurements performed daily. Cells of $D$. vulgaris were subsequently inoculated into the experimental columns from the middle sampling port (between electrodes 3 and 4) utilizing a sterile syringe on Day 5 (Figure 1). Fluid flow was halted for $24 \mathrm{~h}$ after inoculation, to allow time for cells to colonize the column and minimize unwanted flushing of cells from the column. The growth medium was then supplied continuously (as a flow-through with no recirculation) for the experiment duration. A multichannel peristaltic pump was used to maintain a steady flow rate of $\sim 2$ pore volumes per day ( $\sim 40 \mathrm{~cm}$ per day), chosen to replicate realistic flow rates in unconsolidated aquifers [Bear, 1972].

[16] Pore water samples for analysis of aqueous geochemistry were extracted by sterile syringe (new syringe on each occasion) at three sampling ports equipped with reusable septa (a standard aqueous geochemistry rubber stopper designed to be repeatedly pierced by syringe needle to allow fluid extraction) and equally spaced along the column, every $1-2 \mathrm{~d}$ following inoculation (Figure 1). We measured $\mathrm{eH}, \mathrm{pH}$, fluid conductivity, lactate, sulfate, acetate and sulfide concentration. Conductivity, $\mathrm{pH}$ and $\mathrm{eH}$ were measured immediately after sample collection with bench top conductivity (Orion 135A, measurement range: $1 \mu \mathrm{S} / \mathrm{cm}$ to $200 \mathrm{mS} / \mathrm{cm}$ with an accuracy $\pm 0.5 \%$ ), $\mathrm{pH}$ (Hamilton Slimtrode; 3 point calibration $>99 \%$ ), and $\mathrm{eH}$ (MI-800413; eH of the standard quinhydrone solutions: $\pm 20 \mathrm{mV}$ ) probes, respectively. All probes were calibrated prior to each set of measurements using standard solutions. Additional samples were filtered and kept frozen until ion chromatography (IC) analysis was performed for lactate, acetate, and sulfate concentration (estimated maximum error of $\pm 3.5 \mathrm{ppm}$ based on standard deviation of triplicate measurements). A hydrogen sulfide test kit (HACH model HS-WR) with a stated accuracy of $\pm 10 \%$ was used to record aqueous sulfide while making efforts to minimize errors that may occur from sulfide volatilization by immediate sampling and measurement.

[17] Column EC2 was terminated near the end of the anaerobic transition (Day 21) of the experiment to test a scanning electron microscopy (SEM) sampling method for preserving biominerals. Destructive analysis of EC1 was then performed upon completion of the experiment (Day 55) to examine biofilm formation and mineral transformations utilizing SEM equipped with backscattered and secondary electron detectors (energy dispersive X-ray spectroscopy or EDX). A similar method to that of Vandevivere and Baveye [1992] was used to collect the SEM samples in a manner that would help preserve biominerals. Samples were immersed overnight in $2.5 \%$ glutaraldehyde in phosphate buffer solution, rinsed for $4 \mathrm{~h}$ in phosphate buffer, dehydrated through an ascending series of ethanol-water mixtures $(10 \%, 25 \%, 50 \%, 75 \%, 90 \%$, and subsequently in triplicate in $100 \%$ solution for $1 \mathrm{~h}$ each), and finally dried in ambient air. Measurements of the long and short dimensions were performed on three separate biominerals captured in the SEM images, providing both an estimate of the average biomineral dimensions and an estimate of the standard deviation of these estimates.

[18] A two-channel dynamic signal analyzer (DSA) (National Instruments (NI)-4551) was used to perform SIP measurements between 0.1 and $1000 \mathrm{~Hz}$ at 40 equal (in logarithmic space) intervals [Slater and Lesmes, 2002]. We utilized a four-electrode configuration in which the two coiled $\mathrm{Ag}-\mathrm{AgCl}$ electrodes located at either end cap of the column were used for current injection. The resulting potential was recorded for three pairs of adjacent measurement electrodes $(1-2,3-4$, and 5-6) located along the column edge (Figure 1). Phase shift $(\phi)$ and resistivity magnitude $(|\rho|)$ were determined relative to a high precision resistor on channel 1.

[19] Electrodic potential measurements were recorded with a high-impedance digital multimeter (Fluke True RMS multimeter, $50 \mathrm{M} \Omega$ input impedance). To examine both spatial and temporal responses within the columns, we performed three sets of measurements: (a) left coiled electrode $(\mathrm{C} 1)$ as reference while measuring on Electrodes 1 to 6 , (b) right coiled electrode $(\mathrm{C} 2)$ as reference while measuring on Electrodes 1 to 6 and (c) gradient measurements on pairs of electrodes $(1-2,2-3,3-4,4-5,5-6)$ using the first electrode of each pair as the reference. In all cases the reference was connected to the negative terminal of the voltmeter (Figure 1). Note that, with this configuration, a negative open-cell potential is measured when the cathodic reaction occurs on the "reference" located in a region of relatively lower bisufide ion concentration (the polarity being reversed when the reference is at a point of higher bisufide ion concentration). The estimated error in electrodic potentials is $\pm 3 \mathrm{mv}$ based on maximum variations observed during the $5 \mathrm{~d}$ of baseline data.

\section{Spectral Induced Polarization Modeling}

[20] For the Cole-Cole modeling [Cole and Cole, 1941], we used an algorithm that employed a least squares ap- 

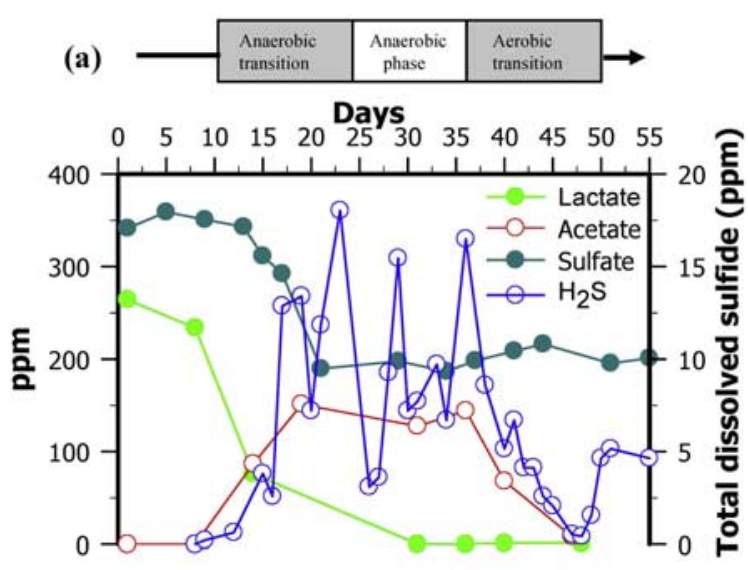

(b) $0 \begin{array}{llll} & & 10 & \text { Days }\end{array}$

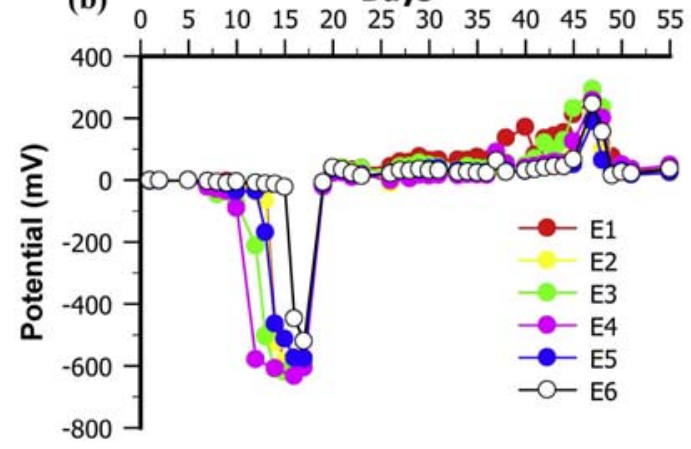

Figure 2. (a) Aqueous chemistry (sulfate, lactate, acetate, and total sulfide) and (b) electrodic potential measurements for the experiment duration. The electrodic potentials are referenced to an $\mathrm{Ag}-\mathrm{AgCl}$ coil in the end cap (C1). Anaerobic and aerobic transitions are shaded. Electrodic potentials exhibit large negative anomalies (up to $-634 \mathrm{mV}$ on Day 16 i.e., $11 \mathrm{~d}$ after inoculation of cells). Positive anomalies (up to $292 \mathrm{mV}$ at Day 47 occur during the aerobic transition). Drops in lactate and sulfate concentrations are concomitant with acetate and sulfide production during the anaerobic phase, indicative of microbial activity. Decreases of acetate and aqueous sulfide are recorded during the aerobic transition. The maximum estimated errors are: $\pm 3.5 \mathrm{ppm}$ for the IC analysis (sulfate, lactate and acetate) based on standard deviation of triplicate measurements; $\pm 10 \%$ for sulfide based on test kit accuracy; $\pm 3 \mathrm{mv}$ for electrodic potential based on maximum observed variations in baseline measurements over a $5 \mathrm{~d}$ period prior to innoculation.

proach with Marquardt regularization [Kemna, 2000] based on equation (3). We recognize that Cole-Cole parameter estimation based on the minimization of a cost function using a least squares criterion is uncertain and may find local minima in the objective function. Bayesian approaches have recently been shown to provide a better approach to Cole-Cole parameter estimation [Ghorbani et al., 2007]. However, analysis of parameter uncertainty suggested that $\tau$ is a well resolved parameter in our modeling (estimated variances being less than $8 \%$ of the parameter estimate) although the variances of the other parameters is considerably greater.

[21] Empirical relations show that these Cole-Cole model parameters are related to pore and grain geometric charac- teristics [Kemna, 2000; Scott and Barker, 2003; Binley et al., 2005]. However, we stress that this is a phenomenological model and the physicochemical significance of the estimated parameters is therefore uncertain [Dias, 2000]. Among the four electrical parameters $\left(\rho_{0}, \tau, m\right.$, and $\left.c\right)$ that define the dispersion between the lower and upper frequency limits, the time constant $(\tau)$ is often the most well resolved parameter [Binley et al., 2005]. The $\tau$ describes the dominant relaxation time and increases with pore or grain size [Schwarz, 1962; Pelton et al., 1978; Wong, 1979; Olhoeft, 1985; Scott and Barker, 2003; Slater et al., 2005] whereas the polarization magnitude, best defined by the normalized chargeability $\left(m_{n}=m / \rho_{0}\right)$ [Lesmes and Frye, 2001], shows a near linear dependence on the interfacial surface area to pore volume $\left(S_{p}\right)$ [Slater et al., 2006]. Here we estimate the spatiotemporal variation in an equivalent polarizable sphere diameter $(d)$, and $S_{p}$ of biomineral phase, using the following relations,

$$
\begin{gathered}
d=2 \sqrt{2 \tau D}, \\
S p^{1.03}=\frac{m_{n}}{3.23}\left(S_{p} \text { in } \mu \mathrm{m}^{-1}\right) .
\end{gathered}
$$

where $D$ is the surface ionic diffusion coefficient. Equation (8) is derived from the electrochemical model of Schwarz [1962] that was developed for colloidal particles in an aqueous suspension. Although this is not a valid model for polarization processes occurring in a porous medium, it may afford some insight into the likely physical length-scale of the charge distribution within the pore space. Furthermore, values of $D$ are inherently uncertain. We use an estimate $\left(D \sim 3 \times 10^{-9} \mathrm{~m}^{2} \mathrm{~s}^{-1}\right)$ given by Tarasov and Titov [2007] obtained from SIP measurements on sands similar to ours with a well defined, narrow grain size distribution. The $S_{p}$ calculation (equation (9)) is based on a strong empirical relationship established from the fit of a Cole-Cole model to geoelectrical data obtained for magnetite $\left(\mathrm{Fe}_{3} \mathrm{O}_{4}\right)$ and zero valent iron $\left(\mathrm{Fe}^{0}\right)$ mixtures [Slater et al., 2006].

\section{Results}

[22] All results reported here are for Column EC1. Column EC2 showed comparable geochemical and geophysical changes during the first $21 \mathrm{~d}$ of the experiment prior to its termination, but for brevity, these changes are not detailed here. The aqueous chemistry (lactate, sulfate, acetate, and total sulfide) during the experiment is summarized in Figure 2a. During the anaerobic transition (first evident in the aqueous geochemistry on Day 9), sulfate and lactate concentration started to drop concurrent with the development of an electrodic potential signal (see details in Figure 2b). By Day 19 lactate concentrations reached very low values $(\sim 1 \mathrm{ppm})$, with the lowest sulfate concentration ( $\sim 190 \mathrm{ppm}$ ) following on Day 21. This drop in lactate and sulfate concentration was concurrent with the production of acetate and sulfide, consistent with anaerobic microbially induced sulfate reduction. Acetate concentration reached its highest value of $\sim 151 \mathrm{ppm}$ at Day 19 . During the aerobic transition (first evident in the aqueous geochemistry on Day 37), acetate concentration declined reaching values as 

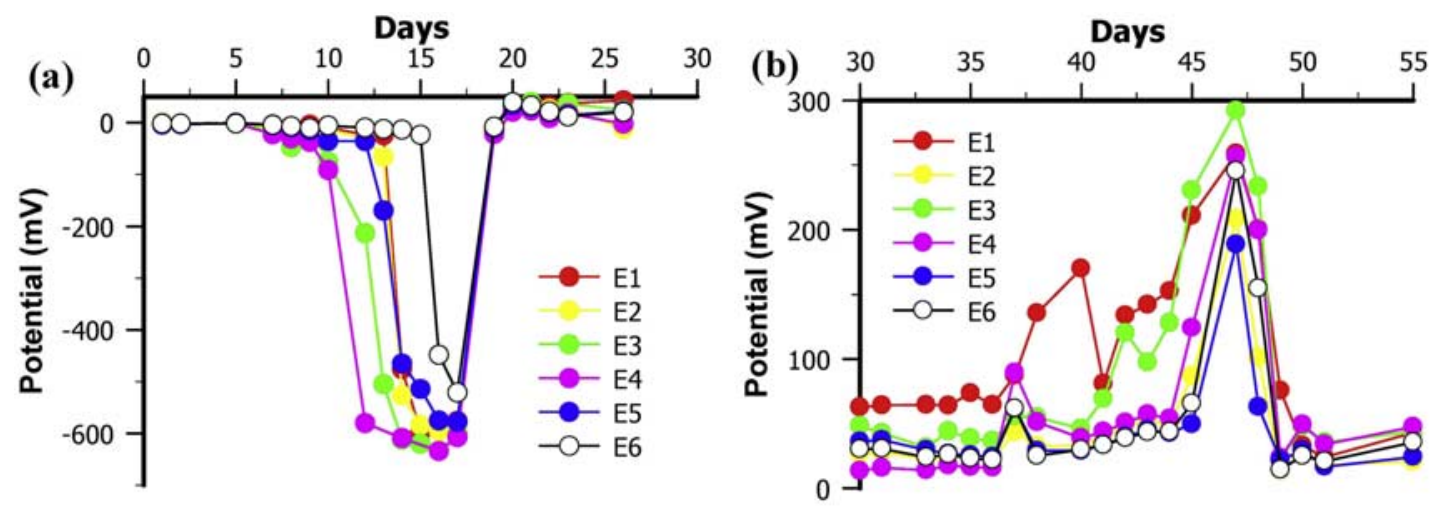

(c)

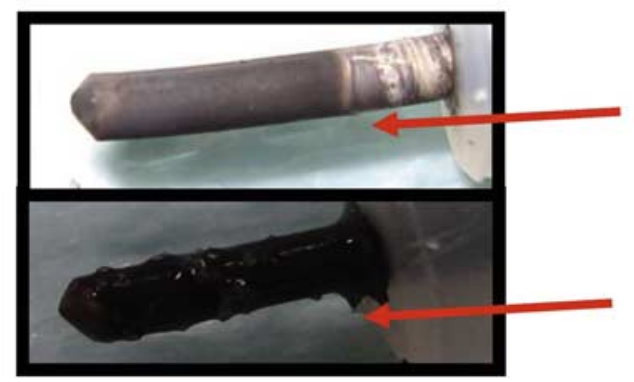

\title{
Clean AgCl electrode away from $\mathrm{HS}^{-}$production
}

\author{
Tarnished electrodes $\left(\mathrm{Ag}_{2} \mathrm{~S}\right)$ \\ in zone of $\mathrm{HS}^{-}$production
}

Figure 3. Electrodic potentials developing during (a) anaerobic transition and (b) aerobic transition, and (c) photographs of electrodes showing clean $\mathrm{AgCl}$ electrode away from $\mathrm{HS}^{-}$production and tarnished electrode $\left(\mathrm{Ag}_{2} \mathrm{~S}\right)$ in zone of $\mathrm{HS}^{-}$production. The electrodic potentials are referenced to an $\mathrm{Ag}-\mathrm{AgCl}$ coil in the end cap (C1). Note that the scales are different in the two figures to highlight the changes observed during both stages. See Figure 2 for plot of the data on a single scale. The estimated error is $\pm 3 \mathrm{mv}$ based on maximum observed variations in baseline measurements over a $5 \mathrm{~d}$ period prior to innoculation.

low as $\sim 8$ ppm by Day 48 . Total dissolved sulfide concentration peaked at $18 \mathrm{ppm}$ on Day 23, exhibiting sequential peaks during the anaerobic phase, but remaining elevated at $8.3 \pm 5.4 \mathrm{ppm}$ from Day 9 to Day 36. Total dissolved sulfide dropped from $16.5 \mathrm{ppm}$ at the onset of the aerobic phase (Day 36) to $0.5 \mathrm{ppm}$ by Day 48, although it later increased to $3.8 \pm 2.3 \mathrm{ppm}$ from Day 37 to Day 55 . The implications of these measurements for the column biogeochemistry are described later in the Discussion.

[23] Electrodic potentials are shown in Figure 2b; a more detailed view of the anaerobic and aerobic transitions is given in Figures 3a and 3b, respectively. For brevity, only the electrodic potential values for measurements made using $\mathrm{C} 1$ as the reference are presented here since similar values are recorded with $\mathrm{C} 2$ as the reference. Gradient electrodic potential measurements provided little additional information because the electrodes were close to each other and because the $\mathrm{HS}^{-}$concentrations between the electrodes were similar (electrodic potentials were thus small). Prior to inoculation, potential values were stable and no significant change was recorded $(-1 \pm 3 \mathrm{mV})$. On Day 10 the electrodic potentials started dropping $(\sim-90 \mathrm{mV})$ near the inoculation point (Electrodes 3 and 4). These electrodic responses coincide with aqueous geochemistry changes as described previously, as well as visual evidence of black precipitate formation (interpreted as microbial-induced iron sulfide according to equations (7) and (8)). Electrodic potentials continued to decrease, reaching $-634 \mathrm{mV}$ on
Day 16 for electrodes 3 and 4. Similar strongly negative electrodic potentials developed at other electrodes during the anaerobic transition, but at later times, consistent with expansion of precipitate toward the column edges. The order in the onset of the electrodic potential is clear in Figure 3a (4, 3, 5, 2, 1, and finally 6$)$ corresponding to the center ( 3 and 4$)$ near the inoculation point, quarter length ( 2 and 5), and far ends of the column (Electrodes 1 and 6) (Figure 1). Figure 4 is a time-sequence of photographs starting with non-inoculated media (Figure 4a, Day 1) during the anaerobic state, showing black precipitate (Figure 4b, Day 36), and evidence of subsequent iron sulfide dissolution during the aerobic transition (Figure 4c, Day 46). On Day 18, when black precipitate was visible along the column length, electrodic potentials began to dissipate and return to baseline values. They then remained relatively steady until the end of the anaerobic phase on Day 36. During the aerobic transition a similar temporal pattern was observed, except that the electrodic potentials are positive, reaching $\sim 300 \mathrm{mV}$ on Day 47 . A rapid decrease was subsequently observed, such that by Day 49 values returned to levels comparable to those of pre-biomineralization (Figure $3 b$ ) and remained relatively steady until the end of the experiment at Day 55. Visual inspection of the $\mathrm{Ag}-\mathrm{AgCl}$ electrodes revealed tarnishing (Figure 3c) at electrodes in the column, indicative of $\mathrm{Ag}_{2} \mathrm{~S}$ formation as per equation (4). 
(a)

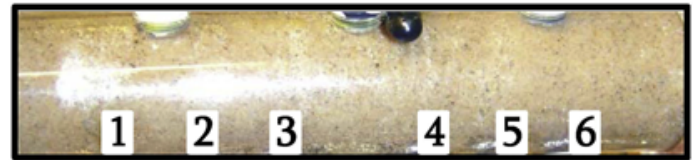

(b)

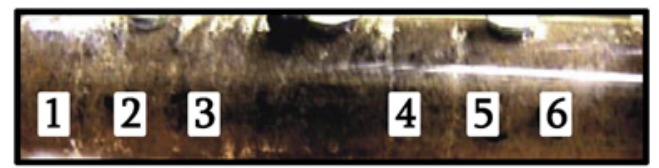

(c)

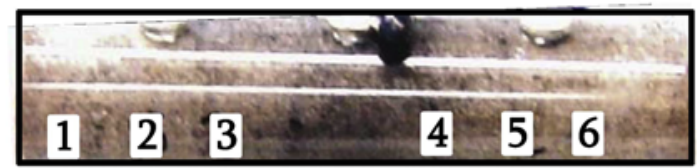

Figure 4. Photos illustrating the observed color changes over time for experimental columns: (a) Day 1, showing clean sand; (b) Day 36, showing widespread Iron sulfide biomineralization; (c) Day 46, showing subsequent dissolution of majority of Iron sulfide. Numbers refer to electrode locations along the column (electrode is in port on side of column that is not shown in photo).

[24] Post-experimental destructive sampling (Day 55) and SEM imaging verified the presence of biominerals (iron sulfide encrusted bacterial cell surfaces) and iron sulfide biofilm formations (mass of biominerals attached on quartz grain) (Figure 5). The SEM imaging revealed visual evidence for iron sulfide precipitates encrusted on biominerals
(Figure 5a), as well as evidence of mineralized biofilms coating sand grains (Figure 5c). The iron sulfide encrusted cells show the characteristic curved, rod-like shape of $D$. vulgaris with an average size (based on the dimensions of three cells captured in three images) of $0.44 \pm 0.06 \mu \mathrm{m}$ and $1.93 \pm 0.15 \mu \mathrm{m}$ in the short and long axis radius, respectively. The supporting EDX analysis conclusively confirmed the presence of iron sulfide in solid state, as expected from equations (5) and (6).

[25] The observed microbial-mineral transformations resulted in significant SIP signatures in agreement with previous results [Williams et al., 2005; Ntarlagiannis et al., 2005]. Figure 6 plots the response observed at all three column locations for six times (Days 17, 19, 22, 36, 37 and 40 ). Note that the data are truncated where the $\phi$ values are less than the instrument accuracy $(0.1 \mathrm{mrad})$. Prior to Day 14 no significant SIP responses were recorded; all measurements lie close to the instrument accuracy $(0.1 \mathrm{mrad})$. The initial lack of an SIP response in the presence of significant electrodic potentials indicative of dissolved sulfide production most likely reflects this limited SIP measurement sensitivity. Between Days 14 and 36 (end of anaerobic phase), a gradual increase was observed in magnitude of $\phi$ and shift of $\phi$ peak to higher frequencies (Figure 6). The spatiotemporal variability of the SIP responses is not perfectly correlated with the observed iron sulfide precipitation. Although all electrode pairs show the same pattern (and similar shifts in frequency of the $\phi$ peak), the $\phi$ magnitudes are different with higher $\phi$ values presumably

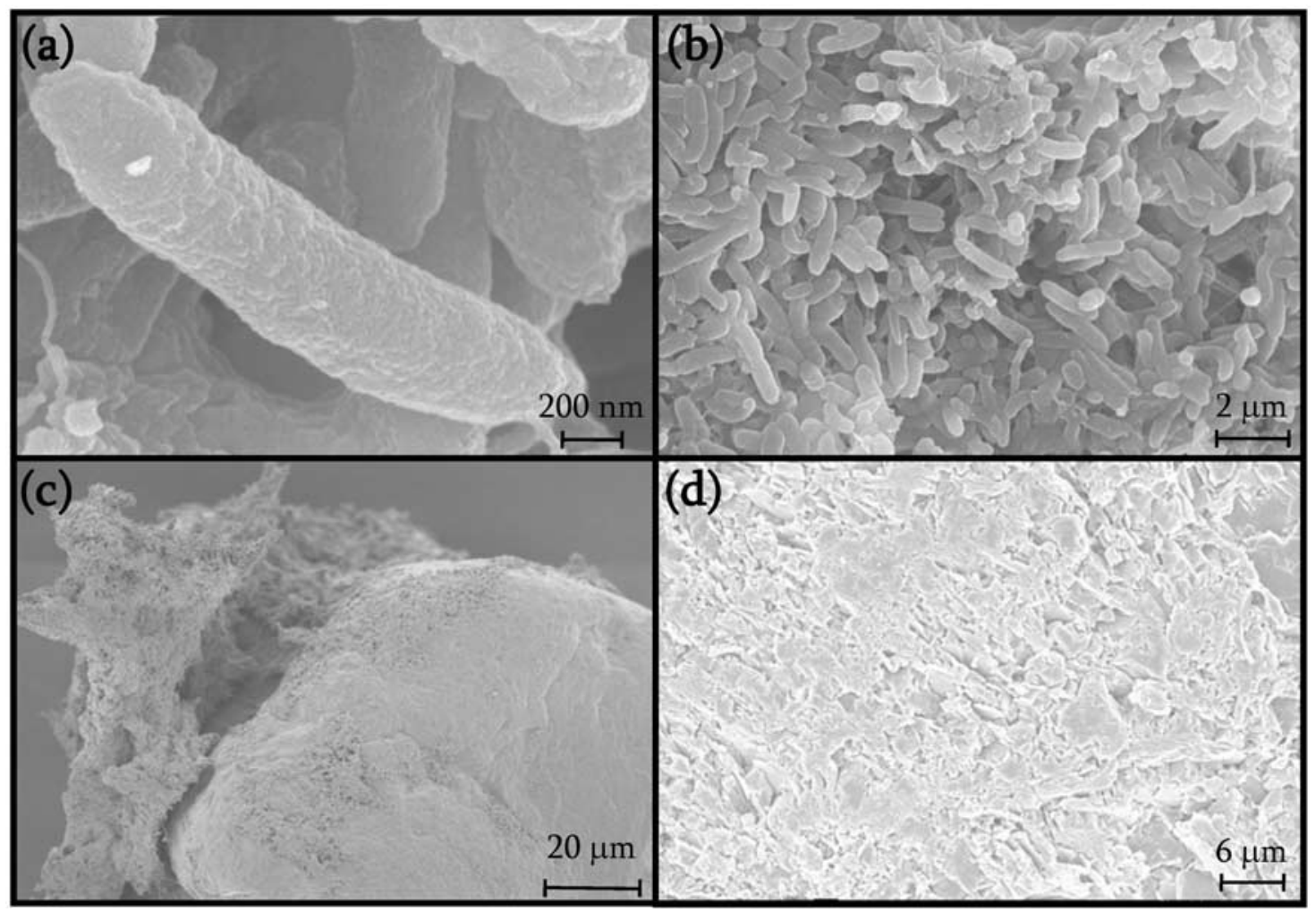

Figure 5. High-resolution scanning electron microscopy (SEM) images of samples obtained via destructive analysis of the column, which was performed at the end of the experiment $(\mathrm{t}=55$ days): (a) Iron sulfide encrusted bacterial cell, i.e., biomineral; (b) iron sulfide biofilm; (c) iron sulfide biofilm encrusted quartz grain; (d) clean quartz surfaces. 
Table 1. Summary of the Modeled Cole-Cole Parameters ${ }^{\mathrm{a}}$

\begin{tabular}{|c|c|c|c|c|c|c|c|c|c|c|c|c|c|c|c|}
\hline \multirow[b]{2}{*}{ Day } & \multicolumn{5}{|c|}{ Pair $1-2$} & \multicolumn{5}{|c|}{ Pair $3-4$} & \multicolumn{5}{|c|}{ Pair 5-6 } \\
\hline & $\rho_{0}$ & $m$ & $\tau$ & $m_{n}$ & RMS & $\rho_{0}$ & $m$ & $\tau$ & $m_{n}$ & RMS & $\rho_{0}$ & $m$ & $\tau$ & $m_{n}$ & RMS \\
\hline 17 & 31.3 & 0.004 & 0.28 & 0.6 & 0.13 & 1.5 & 31.3 & 0.004 & 0.27 & 0.6 & 0.13 & 1.1 & 33.7 & 0.009 & 0.34 \\
\hline 19 & 30.4 & 0.004 & 0.23 & 0.5 & 0.13 & 2.7 & 36.3 & 0.009 & 0.21 & 0.5 & 0.25 & 2.4 & 34.1 & 0.023 & 0.35 \\
\hline 21 & 39.1 & 0.007 & 0.04 & 0.8 & 0.18 & 1.1 & 41.7 & 0.008 & 0.15 & 0.6 & 0.19 & 2.3 & 39.0 & 0.025 & 0.22 \\
\hline 22 & 35.4 & 0.005 & 0.11 & 0.7 & 0.14 & 3.3 & 39.3 & 0.010 & 0.16 & 0.6 & 0.25 & 1.6 & 37.1 & 0.025 & 0.26 \\
\hline 23 & 34.4 & 0.006 & 0.07 & 0.7 & 0.17 & 4.1 & 25.5 & 0.008 & 0.08 & 0.4 & 0.31 & 2.0 & 36.4 & 0.030 & 0.25 \\
\hline 36 & 395. & 0.007 & 0.06 & 0.6 & 0.18 & 3.4 & 39.6 & 0.014 & 0.15 & 0.5 & 0.35 & 0.3 & 36.6 & 0.033 & 0.22 \\
\hline 37 & 35.3 & 0.007 & 0.10 & 0.6 & 0.20 & 2.3 & 35.6 & 0.010 & 0.26 & 0.8 & 0.14 & 1.8 & 39.5 & 0.025 & 0.33 \\
\hline 38 & 38.4 & 0.005 & 0.10 & 0.7 & 0.13 & 0.3 & 38.1 & 0.009 & 0.35 & 0.5 & 0.24 & 0.2 & 42.5 & 0.025 & 0.39 \\
\hline 40 & 34.6 & 0.008 & 0.19 & 0.4 & 0.23 & 1.6 & 33.3 & 0.003 & 0.56 & 0.6 & 0.09 & 0.9 & 35.6 & 0.020 & 0.35 \\
\hline
\end{tabular}

${ }^{a}$ Here $\rho_{0}(\Omega . m)=$ resistivity, $m$ (dimensionless $)=$ chargeability, $\tau(\mathrm{s})=$ time constant $)$, and $m_{n}\left(\times 10^{-3} \mathrm{~S} / \mathrm{m}\right)=$ polarization strength, RMS $(\%$ error between model and data) $=$ Root Mean Square.

sulfide precipitates presenting reduced interfacial surface area for polarization [Ntarlagiannis et al., 2005; Williams et al., 2005]. The equivalent $\phi$ in other parts of the column was $\sim 3$ mrads for Pair 3-4, and $\sim 1 \mathrm{mrad}$ for Pair 1-2. The $\phi$ continued to increase until Day 36 (end of the anaerobic phase), reaching a peak value of $\sim 10$ mrads for Pair 5-6. The equivalent phase shifts were 3 mrads for both Pair 3-4 and Pair 1-2 (Figures 6a-6d). Thereafter, during the aerobic transition, these phase shifts consistently decreased (Figures 6e and 6f), approaching initial (pre-inoculation) values.

[27] The microbial sulfide-mineral transformation resulted in the development of a relatively steep (Cole-Cole $c$ parameter mostly $>0.5$ ) dispersive relaxation. The ColeCole model parameters along with goodness of fit for all data sets $(R M S$ error between model and data, mostly $<5 \%$ ) are summarized in Table 1. Figure 7 illustrates examples of Cole-Cole fits of selected data sets from the three column positions. The modeling fits the $\phi$ data well, although the magnitude $(|\rho|)$ data are poorly fit below $\sim 0.5 \mathrm{~Hz}$. However, we consider the fits remarkably good given the small phase peaks. Cole-Cole modeling of SIP data is normally performed on dispersions where the phase peak is an order of magnitude (or more) greater than what we measure here. Figure 8 shows the variations in the geoelectrical estimates of $d$ and $S_{p}$ obtained from applications of equations (8) and (9). The estimated $S_{p}$ values fall between $0.03 \mu \mathrm{m}$ and $0.30 \mu \mathrm{m}$ and exhibit a temporal variability that is consistent with biomineral formation and dissolution (as we elaborate on in the Discussion section). The highest value $(0.29 \mu \mathrm{m})$ corresponds to the end of the anaerobic phase (Day 36) in the vicinity of Pair 5-6.

[28] Similarly, the variation in polarizable sphere diameter (d) (from $0.03 \mathrm{~mm}$ to $0.12 \mathrm{~mm}$ ) correlates well with biomineralization evolution as a function of time. Consistent with the actual data (Figure 6), the SIP signature generated during biomineral formation under the anaerobic transition appears mostly reversible during the aerobic transition. With the onset of this transition, the estimated $S_{p}$ values show a gradual decrease indicative of the reversible character of the SIP response as a function of time. However, the $S_{p}$ values for Pair 5-6 remain relatively elevated until the end of the experiment, suggesting that the process was not fully reversible within the timeframe of (a)

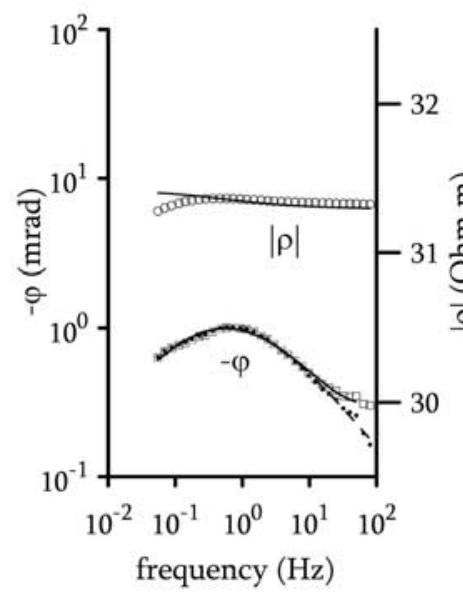

(b)

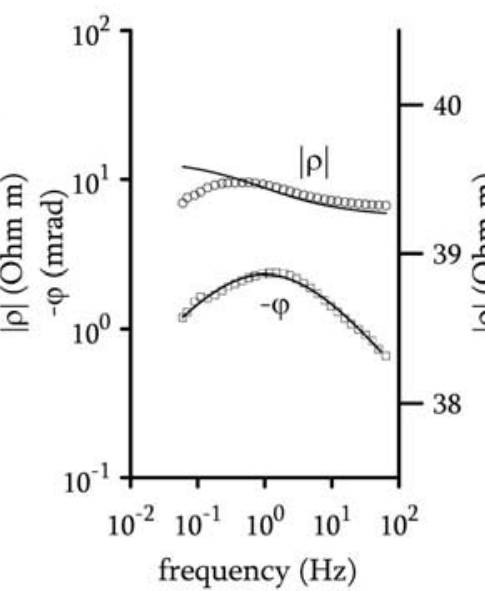

(c)

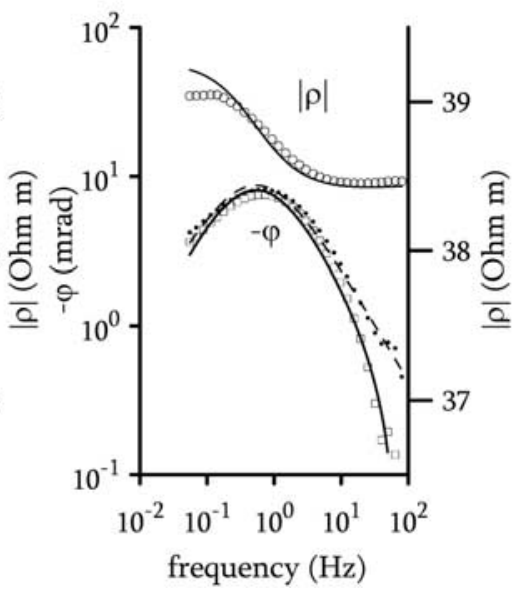

Figure 7. Examples of the fit of the Cole-Cole model to SIP data sets at the three electrode pairs along the column: (a) Pair 1-2 on Day 17 (b) Pair 3-4 on Day 22 (c) Pair 5-6 on Day 21. The decoupled model for the low-frequency polarization (black dots) of interest here is shown for the $\varphi$ when it is significantly different from the measured data. Open symbols are the measured data and lines show the model fit. Note that the $|\rho|$ scale is different in each figure in order to visualize the frequency dependence. 
(a)

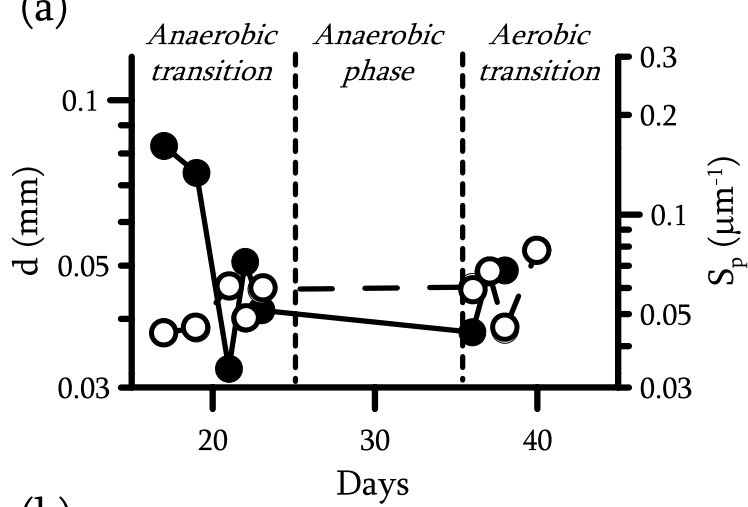

(b)
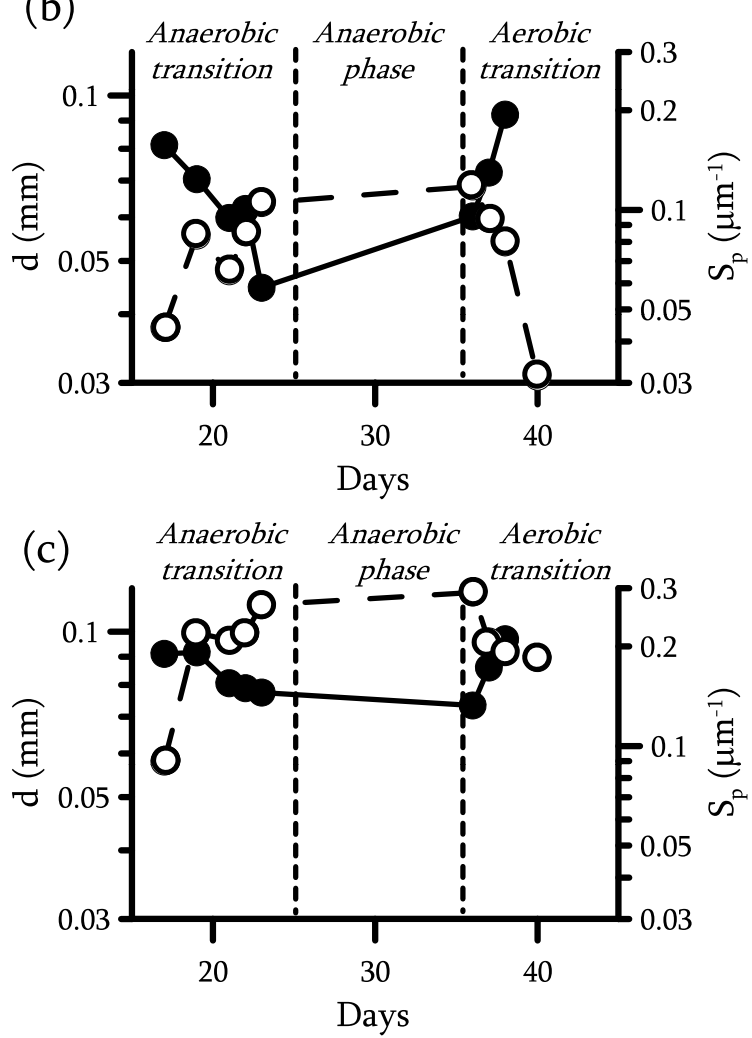

Figure 8. Variation of polarizable sphere diameter $(d)$ and specific surface area to pore volume $(S p)$ estimated from the modeled Cole-Cole parameters as a function of time (black circles $=d$; open circles $=S p$ ) (a) Pair 1-2, (b) Pair 3-4, and (c) Pair 5-6. Experiment phases are also shown.

this experiment. This is consistent with the SEM data that were collected at the end of the experiment showing evidence of remaining biominerals on the grain surface (Figure 5).

\section{Discussion}

[29] The aqueous geochemistry measurements, solidphase analysis and visual observations of the column color changes provide strong evidence that we were successful in generating (a) an anaerobic transition promoting biomineral formation, and (b) a subsequent aerobic transition promoting biomineral dissolution. During the anaerobic transition, high concentrations of total aqueous sulfide $(8.3 \pm 5.4 \mathrm{ppm})$ were produced as a result of the activity of $D$. vulgaris as described above in equation (7). Ledin and Pedersen [1996] reported that dissimilatory sulfate reduction by bacteria is the most kinetically favorable mechanism by which sulfide is produced. Sequential peaks in sulfide concentration may reflect temporally variable, low amounts of release from other sources such as $\mathrm{H}_{2} \mathrm{~S}$ from non-oxidative $\mathrm{FeS}$ leaching [Ahonen and Tuovinen, 1994]. Alternatively, these peaks may simply reflect variations in $\mathrm{HS}^{-}$concentration driven by variable flow rates. The occurrence of quasi-simultaneous iron sulfide precipitation and aqueous sulfide production was expected owing to the low solubility of iron sulfide $\left(\mathrm{K}_{\mathrm{sp}}=10^{-17.2}\right)$. These results are supported by previous studies reporting the very low solubility of metal sulfides and rapid rates of precipitation, thus inferring their effective removal from solution even in the presence of low concentrations of $\mathrm{H}_{2} \mathrm{~S}$ [Ingvorsen and Jorgensen, 1984; Poulson et al., 1997; Drzyzga et al., 2002].

[30] The decline in sulfide after Day 36 can be attributed to an increase in its oxidation by oxygen, thus supporting a successful aerobic transition. Sulfide is unstable and is easily chemically oxidized under aerobic conditions, leading to sulfate production [Vanloon and Duffy, 2005]. Although sulfate remains the most stable form of the chemical oxidation of sulfide when oxygen is the primary oxidant and the $\mathrm{pH}$ varies from neutral to acidic [Nicholson and Scharer, 1994], various intermediate sulfur species such as thiosulfate $\left(\mathrm{S}_{2} \mathrm{O}_{3}^{2-}\right)$ and sulfite $\left(\mathrm{SO}_{3}^{2-}\right)$ may occur during this process [Zehnder, 1988]. We note that $\mathrm{S}_{2} \mathrm{O}_{3}^{2-}$ is known to dissolve $\mathrm{AgCl}$ and could conceivably dissolve the electrode coating if in sufficient concentration (no visible evidence of $\mathrm{AgCl}$ dissolution was observed). Oxidation of iron sulfide over a $\sim 10$ day period (Days 37-47) is supported by previous laboratory studies confirming the extremely rapid rates of pyrrhotite $\left(\mathrm{Fe}_{(1-\mathrm{x})} \mathrm{S}, 0.0<\mathrm{x}<0.125\right)$ oxidation at atmospheric concentrations of $\mathrm{O}_{2}$ and at $22^{\circ} \mathrm{C}$, on the order of 100 times those measured for pyrite $\left(\mathrm{FeS}_{2}\right)$ [Nicholson and Scharer, 1994]. Partial oxidation of $\mathrm{Fe}^{2+}$ by oxygen may also have occurred although no evidence for this reaction (e.g., decrease in solution $\mathrm{pH}$ or visual observations of the characteristic brownish ferric (oxy) hydroxide precipitate) was recorded.

[31] Evidence of both low levels of lactate and $\mathrm{SO}_{4}^{2-}$ in the system during the aerobic transition suggests that anaerobic sulfate reduction was sustained throughout the experiment. Several strains of the genus Desulfovibrio have been shown to be tolerant to low-concentrations of oxygen [Cypionka et al., 1985; Abdollahi and Wimpenny, 1990; Johnson et al., 1997]. As an aerotolerant microbe, D. vulgaris will survive in microaerophillic conditions, thus leading to continuous lactate oxidation and sulfate reduction in the system as observed here. The significant decline in acetate probably results from its consumption by both $D$. vulgaris and aerobic microbes that may have been unintentionally introduced into the column upon exposure to air. Contamination was extremely difficult to avoid at this stage. In fact the influent fluid was turbid (a white to pale gray color) after Day 40, an indicator of contamination by aerobic bacteria. Both aerobic microorganisms and cells of D. vulgaris probably therefore co-existed during this transition. The increase of total sulfide after Day 48 suggests a possible gradual return to an anaerobic state that further 
stimulated the activity of $D$. vulgaris cells. It is plausible that aerobic microbes, in the search for oxygen, chemotactically moved toward the fluid inlet at the column center, favoring anoxic conditions inside the column by consuming the available oxygen. Such chemotactic movement of microbes in the direction of elevated electron acceptor concentration [e.g., Childers et al., 2002] and/or elevated carbon concentration [Williams et al., 2005] is supported by the literature.

[32] One part of our work has further explored the use of a simple electrodic potential measurement utilizing Ag$\mathrm{AgCl}$ electrodes for monitoring microbial activity [Williams et al., 2007]. These electrodic potentials are generated by the presence of $\mathrm{HS}^{-}$gradients in the column. Electrochemical reactions between $\mathrm{HS}^{-}$and the electrode surface then result from the difference in the redox state near the two electrodes making up the pair. Since the pair of electrodes is in electrolytic contact, the voltmeter wiring completes an electrical circuit. As a result of the very high input impedance of the voltmeter, the open-circuit potential or oxidation potential, representing the tendency of spontaneous reactions to proceed at the electrode surface, is recorded. Electrodic potentials were very low and stable $(-1 \pm$ $3 \mathrm{mV}$ ) before cell inoculation, with the first significant electrodic potential anomaly $(\sim-90 \mathrm{mV})$ occurring near the inoculation point concomitantly with the first visible observation of black precipitates in the same part of the column. The most negative electrodic potentials were observed to coincide with Pair $(3-4)$, which straddled the largest gradients in iron sulfide precipitation inferred from visible observations (Figure 4). The fact that the most negative potentials did not coincide with the maximum $\phi$ anomalies (recorded on Pair 5-6) is attributed to the SIP dependence on the geometry of the biomineralization, with higher SIP anomalies favored by more dispersive biomineralization (resulting in high interfacial area) rather than localized intense precipitation [Ntarlagiannis et al., 2005; Williams et al., 2005].

[33] The sign of the electrodic potential during the anaerobic and aerobic transitions results from the polarity of the electrodes at the voltmeter (i.e., negative or positive terminal) relative to the direction of the $\mathrm{HS}^{-}$gradient. During Days 10-18 (anaerobic transition), the negative connection was in a relatively $\mathrm{HS}^{-}$deficient zone whereas during Days 37-48 it was in a zone of elevated $\mathrm{HS}^{-}$ compared to the now relatively oxygenated center of the column. During this aerobic transition, positive electrodic potentials (up to $292 \mathrm{mV}$ at Day 47) coincide with visible evidence of extensive iron sulfide dissolution that will locally increase hydrogen sulfide in solution. We emphasize that these measurements are not dependent on the $\mathrm{HS}^{-}$ concentration itself, but rather the gradient in $\mathrm{HS}^{-}$between the electrode locations. During Days 19-36 (anaerobic conditions and high $\mathrm{HS}^{-}$, Figure 2a) electrodic potentials are low, indicative of a homogeneous distribution of $\mathrm{HS}^{-}$ within the column. The spatiotemporal variability in the electrodic potentials can then be interpreted in terms of spatiotemporal variability in $\mathrm{HS}^{-}$within the column, in turn driven by the spatiotemporal distribution in the microbial community and resulting microbial activity.

[34] We attribute and model the SIP response as an enhancement in interfacial polarization caused by the actual biomineralization itself. The recorded changes in $\phi$ magnitude and relaxation peak are diagnostic of biomineral formation. The initial relaxations (Figure 6a) developed almost simultaneously with visible early stage dispersive precipitate formation indicating iron sulfide formation in the column. The largest $\phi$ spectra for all pairs of electrodes occurred at the end of the anaerobic phase. SIP signatures are thus consistent with dispersive iron sulfide precipitation as a result of microbial activity as described by equations (6) and (7).

[35] Based on electrochemical theory (equation (8)), the time constants are inconsistent with the measured relaxation resulting from the interfacial polarization of the biominerally encrusted cells themselves (Figure 5a). The diameter of the polarizable spheres predicted from equation (8) varies from 0.03 to $0.1 \mathrm{~mm}$ whereas the cells are only $1.93 \pm$ $0.15 \mu \mathrm{m}$ in the long-axis. The predicted diameter is instead on the same order of magnitude as the grain size $\left(d_{50}=\right.$ $0.3 \mathrm{~mm}$ ) of the sand used. However, soils and rocks are different to colloidal suspensions in that the polarization length scale is likely associated with the pore diameter as the charge redistribution is limited by zones of reduced ionic mobility associated with constrictions in pore throats [e.g., Titov et al., 2002]. This explanation is supported by strong empirical relations between $\tau$ and pore diameter in consolidated sandstone [e.g., Scott and Barker, 2003]. SEM images show evidence of iron sulfide precipitates on cell surfaces forming biominerals and encrusting quartz grains (Figure 5c). As biofilms/biominerals accumulated, we assume that the pores and pore throats were progressively lined with polarizable biominerals thereby promoting the dependence of $\tau$ on pore diameter. However, it is unlikely that pore throats were completely blocked by extensive iron sulfide biomineralization in our system since the flow rate exhibited no significant changes $(133.6 \pm 7.4 \mathrm{ml} /$ day $)$ during the anaerobic phase.

[36] We have assumed that the increase in specific surface area to pore volume $\left(S_{p}\right)$ of the polarizable biomineral phase of the column causes the increase in polarization magnitude $\left(m_{n}\right)$ during biomineral formation. We estimated $S_{p}$ (equation (9)) based on previous findings that suggested a single, near-linear dependence of $m_{n}$ on $S_{p}$ for both $\mathrm{Fe}^{0}$ and magnetite $\left(\mathrm{Fe}_{3} \mathrm{O}_{4}\right)$ [Slater et al., 2006]. The assumption of a similar relationship for iron sulfide is in part justified by the fact that previous studies found that the interfacial polarizability of iron minerals was not significantly dependent on mineralogy, with $\mathrm{Fe}^{0}$ and $\mathrm{Fe}_{3} \mathrm{O}_{4}$ showing an identical dependence of $m_{n}$ on $S_{p}$ [Slater et al., 2006]. We infer that the increase in $S_{p}$ and decrease in $d$ thus results from the overall pore size reduction (Figure 8) and pore throat clogging associated with biomineral growth and accumulation during the anaerobic transition. The reverse behavior (decrease in $S_{p}$ and increase in $d$ ) is observed during the aerobic transition and attributed to biomineral dissolution/ detachment from quartz grains and subsequent pore expansion. Peaks in interfacial polarization have previously been shown to correlate with attachment of microbial cells and biofilms to mineral grain surfaces [Davis et al., 2006].

[37] The variability in estimated $S_{p}$, (Figure 6) with Pair 5-6 having the highest values, followed by Pair 3-4, and Pair $1-2$, is assumed to reflect variable amounts of biomineralization occurring within the column. We note that the part of the column straddled by Pair 5-6 (highest $\phi$ ) is 
where the most pronounced dispersive iron sulfide mineralization occurred. The fact that the column appeared visibly blacker in parts around electrode Pair 3-4 (Figure 4b) may reflect localized high density, vein-like precipitation (of reduced $S_{p}$ ) partly driven by preferential flow paths arising where the growth medium first entered the column. During certain times of the experiment, flow was measurably greater toward one outflow, despite efforts that were made to maintain a similar outflow from both ends of the column.

[38] We suggest here that SIP measurements could be used to monitor field scale biomineralization processes. Indeed, very recent studies have illustrated the utility of surface-based SIP data sets for tracking biogeochemical processes in the subsurface at the field scale. Williams et al. [2007b] collected IP data sets at three frequencies $(0.125$, $1,10 \mathrm{~Hz}$ ) along $30 \mathrm{~m}$ surface transects at a Department of Energy uranium-contaminated aquifer near Rifle, Colorado. The geophysical data were collected in conjunction with groundwater and sediment geochemical data prior and subsequent to a biostimulation experiment. The time-lapse geophysical data revealed the development of a phase anomaly in the saturated injection zone $(\sim 3-8 \mathrm{~m}$ below ground surface), where differences in phase relative to baseline conditions of up to $\sim 12 \mathrm{mrad}$ were detected. Comparison of the time-lapse geophysical and geochemical data suggested that the evolution of the phase anomaly coincided over space and time with aqueous and mineralogical changes associated with iron and sulfate reducing processes related to this biostimulation process.

\section{Conclusions}

[39] We have demonstrated how SIP measurements, supported by electrodic potentials on $\mathrm{Ag}-\mathrm{AgCl}$ electrodes, can both be used to monitor microbially stimulated sulfide transformations. Unique geoelectrical signatures were generated as a consequence of iron sulfide biomineralization during the anaerobic state, and were generally reversible when the system returned to aerobic conditions. Whereas the electrodic potential provides a measure of $\mathrm{HS}^{-}$concentration gradients generated by microbial sulfate reduction, the SIP measurements are a direct response to the formation and dissolution of polarizable biominerals. We have shown how phenomenological relaxation modeling, in conjunction with published theoretical and empirical relations, can be used to interpret changes in pore structure (surface area to pore volume and pore diameter) as a result of biomineralization transformations. Whereas the electrodic potential method can only detect processes local to the electrode surface (e.g., in boreholes), the SIP method could potentially be used to image biomineralization transformations occurring in a volume of the earth bounded by electrodes. The potential exists to employ these two methods in parallel for the in situ monitoring of bioremediation, such as for sequestration of heavy metals in the subsurface as metal sulfide precipitates at the field scale.

[40] Acknowledgments. This study was funded by the Department of Energy, Environmental Remediation Sciences Program (ERSP) grant DE-AC03-76SF00098 to S. Hubbard. This material is also based upon work supported by the National Science Foundation under grant 0433739 . Andreas Kemna provided the Cole-Cole relaxation modeling algorithm used here. We gratefully acknowledge the constructive review comments of the original submission of this paper provided by Yuxin Wu (Idaho National Laboratory) and André Revil (Colorado School of Mines).

\section{References}

Abdel Aal, G. Z., E. A. Atekwana, L. Slater, and E. A. Atekwana (2004), Effect of microbial processes on electrolytic and interfacial electrical properties of unconsolidated sediments, Geophys. Res. Lett., 31 , L12505, doi:10.1029/2004GL020030.

Abdollahi, H., and J. W. T. Wimpenny (1990), Effects of oxygen on the growth of desulfovibrio desulfuricans, J. Gen. Microbiol., 136, $1025-1030$.

Ahonen, L., and O. H. Tuovinen (1994), Solid-phase alteration and iron transformation in column bioleaching of a complex sulfide ore, in Environmental Geochemistry of Sulfide Oxidation, ACS Symp. Ser., vol. 550, edited by C. N. Alpers and D. W. Blowers, pp. 79-89, Am. Chem. Soc., Washington, D. C.

Anderson, R. T., et al. (2003), Stimulating the in situ activity of geobacter species to remove uranium from the groundwater of uranium-contaminated aquifer, Appl. Environ. Microbiol., 69, 5884, doi:10.1128/AEM.69. 10.5884-5891.2003

Archie, G. E. (1942), The Electrical resistivity log as an aid in determining some reservoir characteristics, Trans. Am. Inst. Min. Metall. Pet. Eng., $146,54-62$.

Atekwana, E. A., W. A. Sauck, and D. D. Werkema Jr. (2000), Investigations of geoelectrical signatures at a hydrocarbon contaminated site, J. Appl. Geophys., 44, 167-180, doi:10.1016/S0926-9851(98)00033-0.

Atekwana, E. A., D. D. Werkema, J. W. Duris, S. Rossbach, E. A. Atekwana, W. A. Sauck, D. P. Cassidy, J. Means, and F. D. Legall (2004), In-situ apparent conductivity measurements and microbial population distribution at a hydrocarbon-contaminated site, Geophysics, 69, 56-63, doi:10.1190/ 1.1649375 .

Baas-Becking, L. G. M., I. R. Kaplan, and D. Moore (1960), Limits of the natural environment in terms of $\mathrm{pH}$ and oxidation-reduction potentials, J. Geol., 68, 243-284.

Bartlett, J. B., R. W. Rubble, and R. P. Thoma (1937), The influence of hydrogen peroxide treatment on the exchange capacity of Maryland soils, Soil Sci., 44, 123-128, doi:10.1097/00010694-193708000-00002.

Bear, J. (1972), Dynamics of Fluids in Porous Media, Dover, Mineola, N. Y.

Berner, R. A. (1963), Electrode studies of hydrogen sulfide in marine sediments, Geochim. Cosmochim. Acta, 27, 563-575, doi:10.1016/ 0016-7037(63)90013-9.

Binley, A., L. Slater, M. Fukes, and G. Cassiani (2005), The relationship between frequency dependent electrical conductivity and hydraulic properties of saturated and unsaturated sandstone, Water Resour. Res., 41, W12417, doi:10.1029/2005WR004202.

Chelidze, T. L., and Y. Gueguen (1999), Electrical spectroscopy of porous rocks: a review-I. Theoretical models, Geophys. J. Int., 137, 1-15.

Childers, S. E., S. Ciufo, and D. R. Lovley (2002), Geobacter metallireducens accesses insoluble Fe (III) oxide by chemotaxis, Nature, 416, $767-769$.

Cole, K. S., and R. H. Cole (1941), Dispersion and absorption in dielectrics, vol. I: alternating current field, J. Chem. Phys., 9, 341-351, doi:10.1063/ 1.1750906 .

Cypionka, H., F. Widdel, and N. Pfiennig (1985), Survival of sulfatereducing bacteria after oxygen stress, and growth in sulfate-free oxygensulfide gradients, FEMS Microbiol. Ecol., 31, 39-45, doi:10.1111/ j.1574-6968.1985.tb01129.x.

Davis, C. A., E. Atekwana, E. Atekwana, L. D. Slater, S. Rossbach, and M. R. Mormile (2006), Microbial growth and biofilm formation in geologic media is detected with complex conductivity measurements, Geophys. Res. Lett., 33, L18403, doi:10.1029/2006GL027312.

Dias, C. (2000), Developments in a model to describe low-frequency electrical polarization in rocks, Geophysics, 65, 437-451, doi:10.1190/ 1.1444738 .

Drury, W. J. (1999), Treatment of acid mine drainage with anaerobic solidsubstrate reactors, Water Environ. Res., 71, 1244, doi:10.2175/ $106143096 \times 122375$.

Drzyzga, O., R. El Mamouni, S. N. Agatos, and J. C. Gottschal (2002), Dehalogenation of chlorinated ethenes and immobolization of nickel in anaerobic sediment columns under sulfidogenic conditions, Environ. Sci. Technol., 36, 2630, doi:10.1021/es010184x.

Ehrlich, H. L. (1999), Microbes as geologic agents: their role in mineral formation, Geomicrobiol. J., 16, 135, doi:10.1080/014904599270659.

Emery, K. O., and S. V. Rittenberg (1952), Early diagenesis of California Basin sediments in relation to the origin of oil, Bull. Am. Assoc. Pet. Geol., 36, 735-806.

Ghorbani, A., C. Camerlynck, N. Florsch, P. Cosenza, A. Tabbagh, and A. Revil (2007), Bayesian inference of the Cole-Cole parameters from time and frequency-domain induced polarization, Geophys. Prospect., 55 , 589-605, doi:10.1111/j.1365-2478.2007.00627.x. 
Ingvorsen, K., and B. B. Jorgensen (1984), Kinetics of sulfate uptake by freshwater and marine species of Desulfovibrio, Arch. Microbiol., 139, 61, doi:10.1007/BF00692713.

Johnson, M. S., I. B. Zhulin, M. E. R. Gapuzan, and B. L. Taylor (1997), Oxygen-dependent growth of the obligate anaerobe Desulfovibrio vulgaris Hildenborpugh, J. Bacteriol., 179, 5598-5601.

Kemna, A. (2000), Tomographic Inversion of Complex Resistivity - Theory and Application, 176 pp., Der Andere Verlag, Osnabrück, Germany.

Ledin, M., and K. Pedersen (1996), The environmental impact of mine wastes-Roles of microorganisms and their significance in treatment of mine wastes, Earth Sci. Rev., 41, 67-108, doi:10.1016/0012-8252(96)00016-5.

Lesmes, D. P., and K. M. Frye (2001), The influence of pore fluid chemistry on the complex conductivity and induced-polarization responses of Berea sandstone, J. Geophys. Res., 106, 4079-4090, doi:10.1029/ 2000JB900392.

Lovley, D. R., P. K. Widman, J. C. Woodward, and E. J. P. Phillips (1993), Reduction of Uranium by cytochrome of Desulfovibrio vulgaris, Appl. Environ. Microbiol., 3572-3576

Luther, G. W. I., T. F. Rozan, M. Taillefert, D. B. Nuzzio, C. Di Meo, T. M. Shank, R. A. Lutz, and S. Craig Cary (2001), Chemical speciation drives hydrothermal vent ecology, Nature, 410, 813-816, doi:10.1038/ 35071069

Mansoor, N., and L. Slater (2007), On the relationship between iron concentration and induced polarization in marsh soils, Geophysics, 72, A1 A5, doi:10.1190/1.2374853.

Marshall, D. J., and T. R. Madden (1959), Induced polarization: A study of its causes, Geophysics, 24, 790-816, doi:10.1190/1.1438659.

Mehra, O. P., and M. L. Jackson (1960), Iron oxide removal from soils and clays by a dithionite-citrate system buffered with sodium bicarbonate, Clays Clay Miner., 7, 317-327, doi:10.1346/CCMN.1958.0070122.

Minsley, B., J. Sogade, and F. D. Morgan (2007), Three-dimensional selfpotential inversion for subsurface DNAPL contaminant detection at the Savannah River Site, South Carolina, Water Resour. Res., 43, W04429, doi:10.1029/2005WR003996.

Naudet, V., A. Revil, J. Y. Bottero, and P. Bégassat (2003), Relationship between self-potential (SP) signals and redox conditions in contaminated groundwater, Geophys. Res. Lett., 30(21), 2091, doi:10.1029/ 2003 GL018096.

Naudet, V., A. Revil, E. Rizzo, J. Y. Bottero, and P. Bégassat (2004), Groundwater redox conditions and conductivity in a contaminated plume from geoelectrical investigations, Hydrol. Earth Syst. Sci., 8, 8-22.

Nicholson, R. V., and J. M. Scharer (1994), Laboratory studies of pyrrhotite oxidation kinetics, in Environmental Geochemistry of Sulfide Oxidation, ACS Symp. Ser., vol. 550, edited by C. N. Alpers and D. W. Blowes, pp. 14-30, Am. Chem. Soc., Washington, D. C.

Ntarlagiannis, D., K. H. Williams, L. Slater, and S. Hubbard (2005), Lowfrequency electrical response to microbially induced sulfide precipitation, J. Geophys. Res., 110, G02009, doi:10.1029/2005JG000024.

Olhoeft, G. R. (1985), Low-frequency electrical properties, Geophysics, 50 2492-2503, doi:10.1190/1.1441880.

Pelton, W. H., S. H. Ward, P. G. Hallof, W. R. Sill, and P. H. Nelson (1978), Mineral discrimination and removal of inductive coupling with multifrequency IP, Geophysics, 43, 588-609, doi:10.1190/1.1440839.

Pelton, W. H., W. R. Sill, and B. D. Smith (1983), Interpretation of complex resistivity and dielectric data: Part I, Geophys. Trans., 29, 297-330.

Poulson, S. R., P. J. S. Colberg, and J. I. Drever (1997), Toxicity of heavy metals (Ni, Zn) to Desulfovibrio desulfuricans, Geomicrobiol. J., 14, 41.

Providenti, M. A., H. Lee, and J. T. Trevors (1993), Selected factors limiting the microbial degradation of recalcitrant compounds, J. Ind. Microbiol. Biotechnol., 12, 379-395.

Revil, A., and P. W. J. Glover (1997), Theory of ionic surface electrical conduction in porous media, Phys. Rev. B, 55, 1757-1773, doi:10.1103/ PhysRevB.55.1757

Revil, A., and P. W. J. Glover (1998), Nature of surface electrical conductivity in natural sands, sandstones, and clays, Geophys. Res. Lett., 25 691-694, doi:10.1029/98GL00296.

Rittle, K. A., J. I. Drever, and P. J. S. Colberg (1995), Precipitation of arsenic during bacterial sulfate reduction, Geomicrobiol. J., 13, 1.

Schultze-Lam, S., D. Fortin, B. Davis, and T. J. Beveridge (1996), Mineralization of bacterial surfaces, Chem. Geol., 132, 171, doi:10.1016/ S0009-2541(96)00053-8.

Schwarz, G. (1962), A theory of the low-frequency dielectric dispersion of colloidal particles in electrolyte solution, J. Phys. Chem., 66, 2636-2642, doi: $10.1021 / \mathrm{j} 100818 \mathrm{a} 067$

Scott, J. B. T., and R. D. Barker (2003), Determining pore-throat size in Permo-Triassic sandstones from low-frequency electrical spectroscopy, Geophys. Res. Lett., 30(9), 1450, doi:10.1029/2003GL016951.
Slater, L., and A. Binley (2006), Case history - synthetic \& field based electrical imaging of a zerovalent iron barrier: implications for monitoring long-term barrier performance, Geophysics, 71, B129-B137, doi:10.1190/1.2235931.

Slater, L. D., and D. P. Lesmes (2002), IP interpretation in environmental investigations, Geophysics, 67, 77-88, doi:10.1190/1.1451353.

Slater, L. D., J. Choi, and Y. Wu (2005), Electrical properties of iron-sand columns: implications for induced polarization investigation and performance monitoring of iron-wall barriers, Geophysics, 70, G87-G94, doi:10.1190/1.1990218

Slater, L. D., D. Ntarlagiannis, and D. Wishart (2006), On the relationship between induce polarization and surface area in metal-sand and clay-sand mixtures, Geophysics, 71, doi:10.1190/1.2187707.

Sumner, J. S. (1976), Principles of Induced Polarization for Geophysical Exploration, Elsevier Sci., New York.

Tarasov, A., and T. Titov (2007), Relaxation time distribution from time domain induced polarization measurements, Geophys. J. Int., 170, $31-$ 43, doi:10.1111/j.1365-246X.2007.03376.x.

Titov, K., V. Komarov, V. Tarasov, and A. Levitski (2002), Theoretical and experimental study of time domain-induced polarization in watersaturated sands, J. Appl. Geophys., 50, 417-433, doi:10.1016/S09269851(02)00168-4

Vandevivere, P., and P. Baveye (1992), Sampling method for the observation of microorganisms in unconsolidated porous media under scanning electron miscroscopy, Soil Sci., 153, 482,doi:10.1097/00010694199206000-00007.

Vanloon, G. W., and S. J. Duffy (2005), Environmental Chemistry: A Global Perspective, Oxford Univ. Press, New York.

Ward, S. H., B. K. Sternberg, D. J. LaBrecque, and M. M. Poulton (1995), Recommendations for IP research, Leading Edge, 14, 243-247, doi:10.1190/1.1437120.

Ward, O. P., A. Singh, and J. Van Hamme (2003), Accelerated biodegradation of petroleum hydrocarbon waste, J. Ind. Microbiol. Biotechnol., 30 , 260-270, doi:10.1007/s10295-003-0042-4.

Werkema, D. D., Jr., E. A. Atekwana, A. L. Endres, W. A. Sauck, and D. P. Cassidy (2003), Investigating the geoelectrical response of hydracarbon contamination undergoing biodegradation, Geophys. Res. Lett., 30(12), 1647, doi:10.1029/2003GL017346.

Whitfield, M. (1971), A compact potentiometric sensor of novel design: In situ determination of $\mathrm{pH}, \mathrm{pS}^{2-}$ and Eh, Limnol. Oceanogr., 16, 829-837. Williams, K. H., S. Hubbardand, and J. Banfield (2007), Galvanic interpretation of self-potential signals associated with microbial sulfatereduction, J. Geophys. Res., 112, G03019, doi:10.1029/2007JG000440.

Williams, K. H., D. Ntarlagiannis, L. D. Slater, A. Dohnalkova, S. Hubbardand, and J. F. Banfield (2005), Geophysical imaging of stimulated microbial biomineraliztion, Environ. Sci. Technol., 39, 7592-7600, doi:10.1021/ es0504035

Williams, K. H., A. Kemna, M. Wilkins, J. Druhan, E. Arntzen, L. N'Guessan, P. Long, S. Hubbard, and J. Banfield (2007b), Geophysical monitoring of microbial activity during stimulated subsurface bioremediation, Eos Trans. $A G U, 88(52)$, Fall Meet. Suppl., Abstract NS11C-0694.

Wong, J. (1979), An electrochemical model of the induced-polarization phenomenon in disseminated sulfide ores, Geophysics, 44, 1245-1265, doi:10.1190/1.1441005

Wu, Y., L. Slater, and N. Korte (2005), Effect of precipitation on low frequency electrical properties of zero valent iron, Environ. Sci. Technol., 39, 9197-9204, doi:10.1021/es051052x

$\mathrm{Wu}$, Y., L. Slater, and N. Korte (2006), Low frequency electrical properties of corroded iron barrier cores, Environ. Sci. Technol., 40, 2254-2261, doi:10.1021/es0520868

Zehnder, A. J. B. (1988), Biology of Anaerobic Microorganisms, John Wiley, New York.

Zobell, C. E. (1946), Studies on redox potential of sediments, Bull. Am Assoc. Pet. Geol., 30, 477-513.

S. Hubbard, Lawrence Berkeley National Laboratory, Earth Science Division, 1 Cyclotron Road, MS 90-1116, Berkeley, CA 94720, USA.

D. Ntarlagiannis, School of Planning, Architecture, and Civil Engineering, Queen's University Belfast, Belfast BT7 1NN, UK

M. O'Brien, Y. R. Personna, and L. Slater, Department of Earth and Environmental Sciences, Rutgers University, 101 Warren Street, Newark, NJ 07102, USA. (1slater@andromeda.rutgers.edu)

N. Yee, Department of Environmental Sciences, Rutgers University, 14 College Farm Road, New Brunswick, NJ 08901, USA. 